\title{
The Effects of Different Salt Concentrations on the Biochemical Contents of Gracilaria gracilis Greville (Rhodophyta)
}

\author{
Mihriban Özen ${ }^{1 *}$, Ayşegül Kozak², Şükran Dere ${ }^{1}$, İnci Tüney Kızılkaya² \\ ${ }^{1}$ Department of Biology, Faculty of Arts and Sciences, Bursa Uludağ University, 16059, Bursa. \\ ${ }^{2}$ Department of Biology, Faculty of Science, Ege University, 35100, İzmir. \\ *mihribanozen@uludag.edu.tr
}

Received: 18 May 2018

Accepted: 26 September 2018

DOI: $10.18466 /$ cbayarfbe.425013

\begin{abstract}
It has been known that, climate change causes changes in marine water salinity. Since salinity is one of the major factors on osmoregulation and ion concentration of algae, marine algal community will be effected by salinity changes. Gracilaria gracilis samples were collected from Izmir Bay on December 2014. After 2 days adjustment period in the laboratory conditions, the algae samples were divided into 4 groups and each group were cultured in different salinity concentrations $(10 \%$, $25 \%$, $37 \%$ o control group, $48 \%$ o ) for 7 days. On Day 0, 2, 5 and 7, small pieces of samples collected from each group afterwards total protein, phycocyanin, phycoerythrin and chlorophyll a integrity and catalase activity were analyzed. Phycocyanin, phycoerythrin and chlorophyll a levels and catalase activity showed variations according to exposure time and salinity concentrations. Except for the catalase activity, all the parameters were decreased by the end of the 7th day at different salinities. The highest catalase activity was observed on the last day of the experiment in all groups which shows the salinity stress increasement according to exposure time. Gracilaria gracilis was not able to adapt both hiposalinity and hypersalinity conditions.
\end{abstract}

Keywords: Gracilaria gracilis, phycoerythrin, phycocyanin, catalase.

\section{Introduction}

One of the problems that occurs due to climate change is salinity change of the sea water. The Greenhouse effect increases the water temperature and evaporation rates. Depending on the increasing evaporation, the salinity concentration of seawater increases. Salinity is a limiting factor for macroalgae which inhabit intertidal zones and brakishwaters. Besides, salinity is an important factor on metabolism and growth rate of seaweeds and it affects distribution, growth, morphology and chemical composition of algae. Salinity stress might induce the amount of biological active components and changes the metabolic pathway of the organisms which are under stress.

Hyper/Hypo-osmolarity affects the external water potential and effects the ion distribution and turgor pressure adversely. High or low salinity exposure may inhibite cell division and prohibits the growth of the organism [1]. Besides, salinity stress causes inhibitions on photosynthetic activities [2].

Gracilaria has an economic importance for its high agar content. Also, Gracilaria species have antimicrobial activities and produce bioactive metabolites such as primer components [3] and contain important fatty acids like arylic acid and eicosonoids which have important roles in oxydative pathways [4]. Gracilaria is a common alga of the intertidal zone of Izmir Bay.

In this study, we aim to determine the effects of salinity stress on the red alga Gracilaria gracilis Greville. The algae samples were exposured to different salt concentrations and total protein (TP), phycocyanin (PC), phycoerythrin (PE) levels and catalase activity were analysed. We believe that this study might contribute to determining the effects of salinity on macroalgae. As a result, we may predict how macroalgae will respond to salinity changes occured depending on global warming.

\section{Materials and Methods \\ 2.1. Sample collection and preparation}

The Gracilaria gracilis samples were collected from İzmir Bay on December 2014. The water temperature (T), salinity, electrical conductivity (EC) and $\mathrm{pH}$ of sampling point were measured using a multi parameter probe (CyberScan 600, EUTECH Instruments). Probes were calibrated before the process.

The samples transferred to the laboratory were washed with artificial seawater and their epiphytes were cleaned using toothbrush. The samples were incubated in 
artificial seawater in an aquarium for 2 days for acclimatization before the experiment. $G$. gracilis samples were divided into 4 groups (Figure 1). The artificial seawater was prepared using the sea salt (Red Sea coral pro salt) at the desired concentration. After filtration, 1/4 strength Provasoli enrichment medium [5] and other vitamins were added. The artificial seawater in culture aquariums was changed every three days.

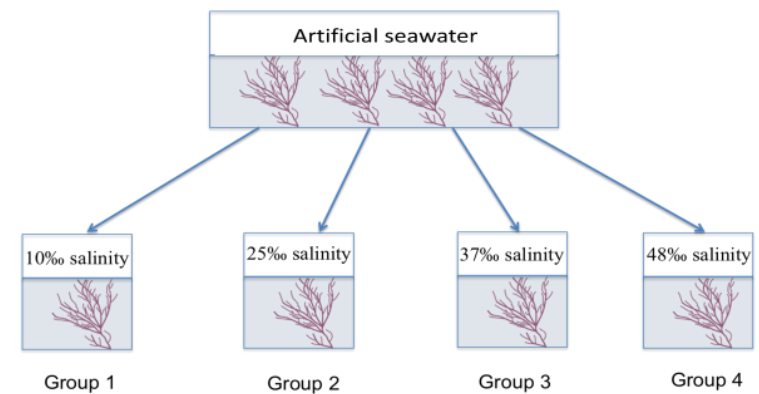

Figure 1. Experimental design of the aquariums.

\subsection{Experimental design and analysis}

After 2 days acclimatization period, total protein (TP), phycocyanin (PC), phycoerythrin (PE) and chlorophyll a (Chl a) content and catalase activity of the samples were analyzed and recorded as Day 0. All the samples were transferred into experimental aquariums which were differ only by their salinity levels. Group 1, 2, 3 and 4 had 10\%o, 25\%o, 37\%o (control group) and \%o 48 salinity concentrations, respectively. The same analyses which were conducted on Day 0 were repeated on $2^{\text {nd }}$, $5^{\text {th }}$ and $7^{\text {th }}$ days.

TP content of the samples were estimated by Bradford method [6]. Bovine serum albumin standards ranging in concentration from $0.05-0.5 \mathrm{mg} / \mathrm{ml}$ were run simultaneously with the test samples.

PC and PE amounts were analyzed according to Beer and Eshel [7]. After samples were extracted with $0.1 \mathrm{M}$ phosphate buffer, the absorbance of the supernatants at different wavelengths $(455 \mathrm{~nm}, 564 \mathrm{~nm}, 592 \mathrm{~nm}, 618 \mathrm{~nm}$, $645 \mathrm{~nm}$ ) were measured and quantities of PC and PE in the samples were determined.

Chl a was analyzed according to Meeks [8] and Catalase activity was analyzed according to Maksimovic and Zivanovic [9].

\section{Results}

Four different parameters (water temperature, $\mathrm{pH}$, electrical conductivity, salinity) were considered during the measurement of water quality in the sampling point. The water temperature was $15^{\circ} \mathrm{C}$ and the $\mathrm{pH}$ was 7.9. Salinity was measured as $37.73 \%$ and the electrical conductivity was $53.82 \mathrm{mS} / \mathrm{cm}$ (Table 1 ).

After 2 days readjustment of the collected samples, they settled into 4 different aquariums with different salinity concentrations. Physical and chemical parameters of the artificial seawater in the culture aquariums were measured (Table 1).

Table 1. Physical and chemical parameters in the sampling point and the culture aquariums.

\begin{tabular}{|c|c|c|c|c|c|}
\hline $\begin{array}{c}\text { Physical } \\
\text { and } \\
\text { chemical } \\
\text { parameters }\end{array}$ & $\begin{array}{c}\text { The } \\
\text { sampling } \\
\text { point }\end{array}$ & $\begin{array}{c}\text { G1* } \\
(10 \% \text { \% })\end{array}$ & $\begin{array}{c}\text { G2 } \\
(25 \%)\end{array}$ & $\begin{array}{c}\text { G3 } \\
(37 \% \%)\end{array}$ & $\begin{array}{c}\text { G4 } \\
(48 \%)\end{array}$ \\
\hline Salinity (\%o) & 37.73 & 10.62 & 25.02 & 36.94 & 48.83 \\
\hline $\begin{array}{l}\text { Temperature } \\
\left({ }^{\circ} \mathrm{C}\right)\end{array}$ & 15.0 & 19.0 & 19.0 & 18.7 & 18.8 \\
\hline $\mathrm{pH}$ & 7.9 & 7.61 & 7.68 & 7.64 & 7.63 \\
\hline $\begin{array}{l}\text { Electrical } \\
\text { conductivity } \\
(\mathrm{mS} / \mathrm{cm})\end{array}$ & 53.82 & 16.62 & 37.26 & 52.13 & 66.34 \\
\hline
\end{tabular}

The highest TP content was measured in Group 4 on Day 2 as $88.47 \pm 0.781 \mathrm{mg} / \mathrm{g}$ wet weight and the lowest value was on Day 7 as $2.35 \pm 0.384 \mathrm{mg} / \mathrm{g}$ wet weight in the same group. In Day 2 all other groups also showed the highest TP content among the each groups. On Day 5 the TP content was started to decrease and on Day 7 the lowest measurements were obtained for all the groups (Table 2; Figure 2).

Table 2. PE, PC, TP and $\mathrm{Chl}$ a and catalase analysis results of all groups.

\begin{tabular}{ccccccc}
\hline Group & Day & PC $(\mathbf{m g} / \mathbf{g})$ & PE $(\mathbf{m g} / \mathbf{g})$ & TP $(\mathbf{m g} / \mathbf{g})$ & $\begin{array}{c}\text { Catalase activity } \\
(\mathbf{U} / \mathbf{m g})\end{array}$ & Chl a (mg/g) \\
\hline & 0 & $0.155 \pm 0.013$ & $1.635 \pm 0.219$ & $32.19 \pm 13.160$ & $0.427 \pm 0.241$ & $0.421 \pm 0.22$ \\
$\mathbf{1}(\mathbf{1 0 \%})$ & 2 & $0.052 \pm 0.022$ & $0.734 \pm 0.229$ & $73.22 \pm 3.853$ & $0.438 \pm 0.002$ & $\mathbf{0 . 3 4 1} \pm \mathbf{0 . 0 6}$ \\
& 5 & $0.057 \pm 0.025$ & $0.679 \pm 0.208$ & $32.44 \pm 1.669$ & $0.565 \pm 0.110$ & $0.180 \pm 0.02$ \\
& 7 & $0.009 \pm 0.004$ & $0.385 \pm 0.111$ & $5.24 \pm 1.555$ & $3,064 \pm 0.122$ & $0.172 \pm 0.01$ \\
\hline & 0 & $0.155 \pm 0.013$ & $1.635 \pm 0.219$ & $32.19 \pm 13.160$ & $0.427 \pm 0.241$ & $0.421 \pm 0.22$ \\
$\mathbf{2}(\mathbf{2 5 \% )})$ & 2 & $0.110 \pm 0.042$ & $0.888 \pm 0.340$ & $79.95 \pm 7.174$ & $0.057 \pm 0.013$ & $0.202 \pm 0.02$ \\
& 5 & $0.096 \pm 0.029$ & $1.035 \pm 0.263$ & $65.04 \pm 1.463$ & $2.292 \pm 0.006$ & $0.217 \pm 0.03$ \\
\hline $\mathbf{3 ~ ( 3 7 \% )}$ & 7 & $0.005 \pm 0.001$ & $0.356 \pm 0.177$ & $5.84 \pm 1.034$ & $\mathbf{1 5 . 3 1 6} \pm \mathbf{0 . 5 5 5}$ & $0.270 \pm 0.02$ \\
\hline
\end{tabular}




\begin{tabular}{ccccccc} 
& 2 & $\mathbf{0 . 1 9 6} \pm \mathbf{0 . 0 0 6}$ & $\mathbf{2 . 0 4 8} \pm \mathbf{0 . 2 2 5}$ & $87.96 \pm 3.339$ & $0.521 \pm 0.124$ & $0.144 \pm 0.002$ \\
& 5 & $0.118 \pm 0.010$ & $1.238 \pm 0.099$ & $48.09 \pm 7.643$ & $0.667 \pm 0.021$ & $0.192 \pm 0.02$ \\
& 7 & $0.005 \pm 0.000$ & $0.421 \pm 0.154$ & $2.76 \pm 0.543$ & $1.662 \pm 0.256$ & $0.275 \pm 0.02$ \\
\hline & 0 & $0.155 \pm 0.013$ & $1.635 \pm 0.219$ & $32.19 \pm 13.160$ & $0.427 \pm 0.241$ & $0.421 \pm 0.22$ \\
$\mathbf{4 ( 4 8 \% )}$ & 2 & $0.125 \pm 0.012$ & $1.151 \pm 0.143$ & $\mathbf{8 8 . 4 7} \pm \mathbf{0 . 7 8 1}$ & $0.440 \pm 0.845$ & $0.407 \pm 0.03$ \\
& 5 & $0.100 \pm 0.014$ & $1.124 \pm 0.174$ & $72.29 \pm 1.255$ & $3.299 \pm 0.678$ & $0.265 \pm 0.02$ \\
& 7 & $0.014 \pm 0.044$ & $0.602 \pm 0.044$ & $2.35 \pm 0.384$ & $2.927 \pm 0.561$ & $0.225 \pm 0.01$ \\
\hline
\end{tabular}

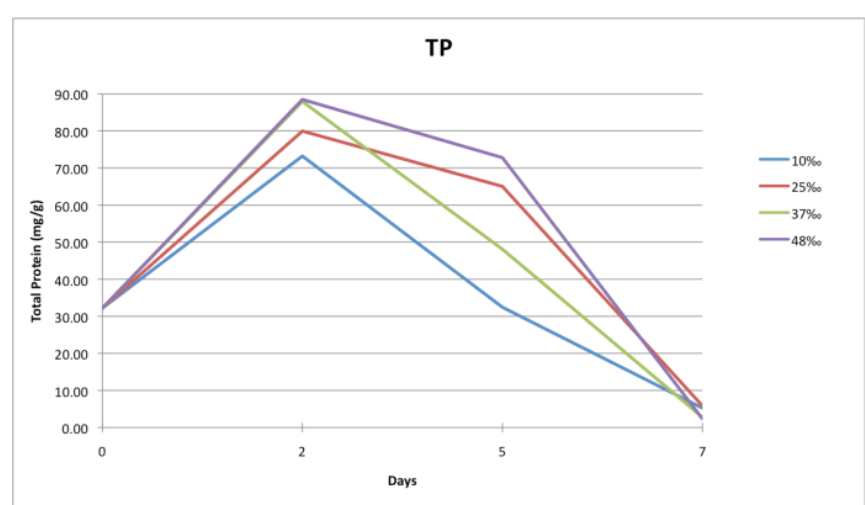

Figure 2. Total protein composition of G. gracilis exposed to different salinities.

PC and PE contents were decreased after Day 0 for all the groups except Group 3. The highest PC and PE amounts were measured in Group 3 on Day 2. Afterwards the PC and PE values decreased as seen in the other groups (Table 2). The PC amount decline in all groups in Day 2 whereas Group 3 showed a distinct increase. On Day 5 all the groups exhibited a decreasing pattern of PC content and continued on Day 7 to decline (Figure 3). The similar results for PE content of $G$. gracilis exposed to different salinity concentrations were obtained. The interesting result was obtained again in Group 3 on Day 2 with a considerable increase of PE content (Figure 4).

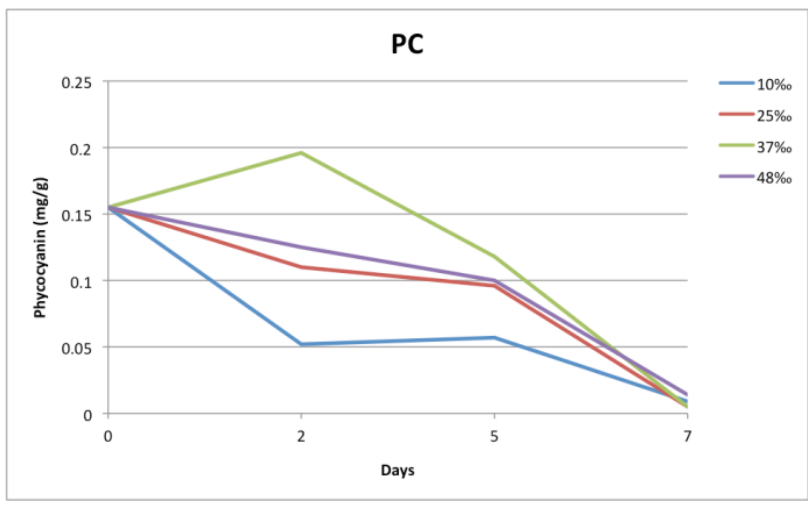

Figure 3. Phycocyanin composition of G. gracilis exposed to different salinities.

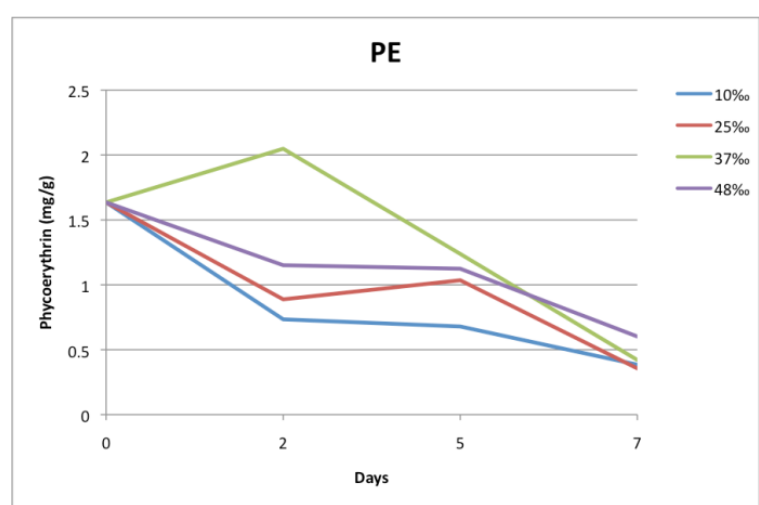

Figure 4. Phycoerythrin composition of G. gracilis exposed to different salinities.

G. gracilis showed decline in $\mathrm{Chl}$ a content at $25 \%$ and $37 \%$ and merely decline at $10 \%$ and $48 \%$ salinities in second experimental day. On Day 5, 25\%o and 37\%o salinities showed a small increase of $\mathrm{Chl}$ a content according to Day 2. On the other hand, $10 \%$ and $48 \%$ salinities showed a clear decrease in Chl a. On the last day of the experiment, Chl a content of the $25 \%$ and $37 \%$ salinities continue to increase while latter group's chl a content were decreasing (Table 2; Figure 5).

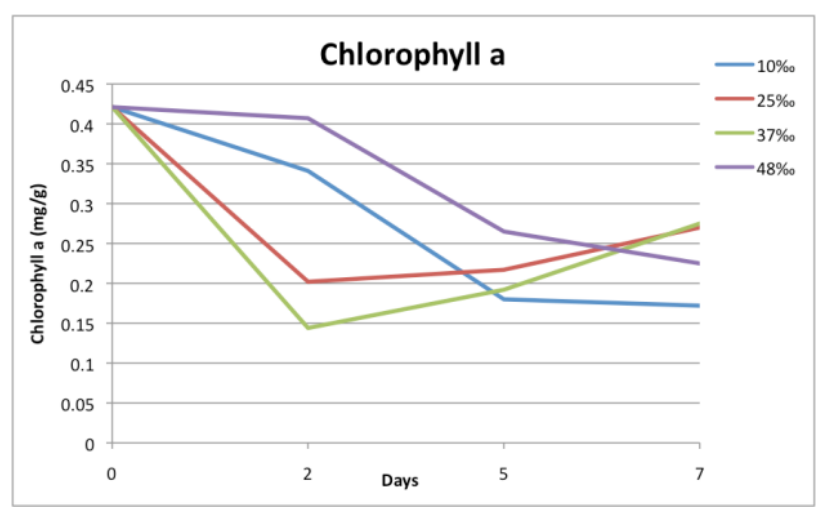

Figure 5. Chlorophyll a composition of G. gracilis exposed to different salinities.

Except for the group 4, the highest catalase levels were determined on the last day of the experiment within the other groups (Figure 6). The highest catalase level among all groups was obtained in Group 2 which has 35 times higher catalase activity than Day 0. First group which was exposed to $10 \%$ salt concentration did not showed a noticable increase until the 7 th day. It was the same for Group 2 which showed a marginal rise of 
catalase on the last day. Third group did not show a remarkable response as the other groups. The last group which was the hypersalinated one gave a raised activity on the 5th day but it decreased on day 7 .

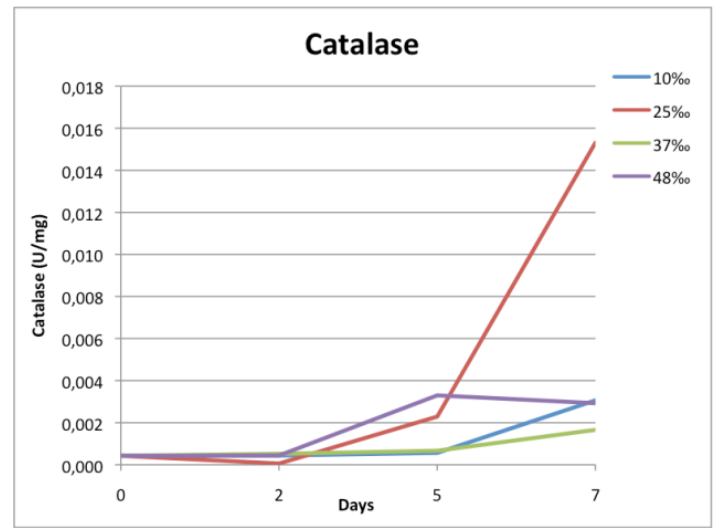

Figure 6. Catalase amounts of G. gracilis exposed to different salinities.

\section{Discussion}

Seaweeds contain three major photosynthetic pigments; carotenoids, chlorophylls and phycobilins. Phycobilins are important protein complexes anchored to tyllakoid membranes. They consist of allophycocyanine, phycocyanin and phycoerythrin. Therefore we determined the effects of salinity on PE, PC and $\mathrm{Chl}$ a integrity which are important components of photosynthetic apparatus. Bhar et al. [10] mentioned about the way photosynthetic pigment variations with varied salinity gradients and causes alternations in chlorophyll content in mangrove plants. Their results also revealed that the mangroves from the high salinity regions have lower pigment concentrations while low salinity region plants have high pigment levels. They concluded that salinity causes chlorophyll degradation in photosynthetic organisms. Cetin [11] reported that salinity stress affected the amount of chlorophyll a in Polysiphonia morrowii species. In that study, hyposalinity stress lead to an increase in chlorophyll a amount while hyper-salinity stress caused a decrease. The decrease in chlorophyll content at high salinity may result from increased chlorophylase activity or changes in the lipid protein ratio of the pigment-protein complex [12]. In our experiment, the Chl a amounts of all the groups were analyzed and it was reported a decline on the seventh day (Figure 5). On the second day, Group 1 and 4 showed a slower decrease while group 2 and 3 displayed an apparent one. Group 3 could tolerated the decline in chlorophyll content after the second day because it was control group. Group 3 and group 2, the salinity concentration close to the control, had an increased graph on the 5th day and the increase in the graph continued on the seventh day. Group 1 and 4 displayed a permanent decline during all days. Eventually, it was obtained decreasing chlorophyll results with the hyper-salinity stress which is consistent with Bhar et al. [10] and Çetin [11]'s studies. But contrary to these studies, a decrease in chlorophyll content was observed at hypo-salinity stress. It was thought that $G$. gracilis could not adapt to the changes in salinity.

As described before Gracilaria sp. grown well in the salinity ranges between $25 \%$ and $35 \%$ [13, 14, 15]. Thus in this study $G$. gracilis samples were grown in salinities ranging from $10,25,37$ and $48 \%$. Israel, Martinez-Goss, and Friedlander [16] and Kim, Kraemer, Neefus, Chung, \& Yarish [17], reported the accumulation of phycobiliproteins as a response to induced salinity stress although Macler [18] observed a decrease on PC and PE levels during hypo and hyper salinity conditions. Besides, Kumar et al. [15] did not obtained a significant increase of PE and PC levels in hypo-saline conditions as compared to hyper-saline ones. Our findings were congruent with Kumar et al. [15] and Macler [18]'s results while we have decreased $\mathrm{PC}$ and PE levels in all groups.

Lu and Vonshak [19] studied effects of salinity on Spirulina platensis and found PC and PE degredation according to increased salinity levels. On the fifth day of their experiment they observed a dramatic decrease of total protein amount and chloropyll integrity. Afterwards they emphasized that the total protein decrease might be an evidence of chloropyll break down. Our results were similar with the results of $\mathrm{Lu}$ and Vonshak [19], total protein variation is consistent with the chloropyll integrity. Also PE and PC levels were decreased with TP levels. In the first group the PC and PE values were nearly 50\% decreased from the beginning (Day 2). The decline continued on Day 5 and the lowest PC and PE results were observed within Group 1 on 7 th day. The same results were obtained with Group 2 and 4 although Group 3 gave different results. Contrary to other groups it was obtained that the highest PC and PE amounts were in Group 3 on second day. On Day 5 the PC and PE levels started to decreased but they were still higher than Day 0. On Day 7 the PC and PE levels were similar to the other groups. Khan [20] and Gomes, Suzuki, Cunha, and Tullii [21] highlighted that saline stress slows down the pigment production. Besides they showed the photosynthetic apparatus degradation in transmission electron microscopy images and they suggested that this may have contributed to the reduction in the content of photosynthetic pigments.

If pigment accumulation is a response to salinity stress as introduced on previous studies [15, 17], our results supports this only at the beginning of the exposure. Later on $G$. gracilis couldn't able to adapted the different salinity levels and showed a decrease for PC, $\mathrm{PE}$ and $\mathrm{Chl}$ a levels. Our results were compatible with Macler [18], who observed a decrease in the level of 
PC, PE and chlorophyll. Phycobilins are good antioxidant substances [22]. Increasing the amount of $\mathrm{PC}$ and PE may indicate that species exhibit adaptations to environmental stress.

When the catalase activity results are considered, the less stress was observed in the third group which have a similar salinity with the sampling area. Third group was followed by first group, which represents the hyposaline salinity within the groups. As it reported in the catalase activity results $G$. gracilis species was tolerate hiposaline conditions other than the hypersaline ones.

As reported in many studies, increased salinity levels in seawater would affect the seaweed communities. In this study, it was researched the response of a common red algae which has an economical importance in all over the world, against hypo and hyper salinity conditions. Our results showed that $G$. gracilis could not adapt salinity changes.

\section{References}

1. Graham, L.E, Graham, J. M, Wilcox, L.W, Algae. San Francisco, Benjamin Cummings 2009.

2. Kirst, G.O, Salinity tolerance of eukaryotic marine algae, Annual Reviews in Plant Physiology and Plant Molecular Biology,1989, $41,21-53$.

3. Hemmingson, J.A, Furneaux, R.X, Murray-brown, V.H Biosynthesis of agar polysaccharides in Gracilaria chilensis bird, McLachlan et Olivira. Carbohydrate Research, 1996, 287, 101115

4. Imbs, A.B, Vologodskaya, A.V, Nevshupova, N.V Khotimchenko, S.V, Titlyanoy, E. A, Response of prostaglandin content in the red alga Gracilaria verrucosa to season and solar irradiance, Phytochemistry, 2001, 58, 1067-1072.

5. Provasoli, L, Media and prospects for the cultivation of marine algae: Cultures and collections of algae, Proceedings of the USJapan Conference, Hakone, 1966, Japanese Society Plant Physiology, 1968, pp.63-75.

6. Bradford, M, A Rapid and Sensitive Method for the Quantitation of Microgram Quantities of Protein Utilizing the Principle of Protein-Dye Binding, Analytical Biochemistry, 1976, 72, 248 254.

7. Beer, S, Eshel, A, Determining phycoerythrin and phycocyanin concentrations in aqueous crude extracts of red algae. Australian Journal of Marine and Freshwater Research, 1985, 36(6), 785 . 792.

8. Meeks, J.C, Castenholz, R.W, Growth and photosynthesis in an extreme thermophile Synechococcus lividus (Cyanophyta) Archives fur Microbiologie, 1971, 78, 25-41.

9. Maksimović J.J.D, Živanović B.D, Plant Salt Tolerance Methods in Molecular Biology (Methods and Protocols). In: Shabala S, Cuin T, (eds), Quantification of the Antioxidant Activity in Salt-Stressed Tissues, Totowa, NJ, Humana Press, 2012.

10. Bhar, S, Chakraborty, D, Ram, S. S, Das, D, Chakraborty, A, Sudarshan M, Santa, S.C, Spatial variation of chlorophyll integrity in a mangrove plant (Excoecaria agallocha) of Indian Sundarban, with special reference to leaf element and water salinity, IOSR Journal Of Environmental Science, Toxicology And Food Technology, 2013, 3(5), 24-31.

11. Cetin, M, Polysiphonia morrowii Harvey Türü Üzerine Tuzluluğun Etkileri, Uludağ Üniversitesi Fen Bilimleri Enstitüsü, Yüksek Lisans Tezi, (yayınlanmamış) 2014, Bursa, Türkiye.

12. Iyengar, E.R.R, Reddy, M.P, Photosynthesis in high salt-tolerant plants. Ed.: Pesserkali, M, Hand Book of Photosynthesis, Marshal Dekar, Baten Rose, USA, 1996, 56-65.

13. Nelson, S. G, Tsutsui, R. N, Best, R.R, Evaluation of seaweed mariculture potential in Guam: I. Ammonia uptake by growth of two species of Gracilaria (Rhodophyta), University of Guam Marine Laboratory Technology Reports, 1980, 61, 1-20.

14. Phooprong, S, Ogawa, H, Hayashizaki, K, Photosynthetic and respiratory responses of Gracilaria salicornia (C. Agardh) Dawson (Gracilariales, Rhodophyta) from Thailand and Japan, Japanese Journal of Applied Phycology, 2007, 19, 795-801.

15. Kumar, M, Kumari, P, Gupta, V, Reddy, C, Jha, B, Biochemical responses of red alga Gracilaria corticata (Gracilariales, Rhodophyta) to salinity induced oxidative stress, Journal of Experimental Marine Biology and Ecology, 2010, 391, 27-34.

16. Israel, A, Martinez-Goss, M, Friedlander, M, Effect of salinity and $\mathrm{pH}$ on growth and agar yield of Gracilaria tenuistipitata var. liui in laboratory and outdoor cultivation, Journal of Applied Phycology, 1999, 11, 543-549.

17. Kim, J. K, Kraemer, G. P, Neefus, C. D, Chung, I. K, Yarish, C, Effect of temperature and ammonium on growth, pigment production and nitrogen uptake by four species of Porphyra (Bangiales, Rhodophyta) native to the New England coast, Journal of Applied Phycology, 2007, 19, 431-440.

18. Macler, B.A, Salinity effects on photosynthesis, carbon allocation and nitrogen assimilation in the red alga Gelidium coulteri, Plant Physiology, 1988, 88, 690-694.

19. Lu, C, Vonshak, A, Effects of salinity stress on photosystem I function in cyanobacterial Spirulina platensis cells, Physiologia Plantarum, 2002, 114, 405-413.

20. Khan, N.A, Na-Cl inhibited chlorophyll synthesis and associated changes in ethylene evolution and antioxidative enzyme activities in wheat, Biologia Plantarum, 2003, 47(3), 437-440

21. Gomes, M. C, Suzuki, M.S, Cunha, M, Tullii C.F, Effect of salt stress on nutrient concentration, photosynthetic pigments, proline and foliar morphology of Salvinia auriculara Aubl., Acta Limnologica Brasiliensia, 2011, 23(2), 164-176.

22. Cano-Europa, E, Ortiz-Butrón, ., Gallardo-Casas, C.A, BlasValdivia, V, Pineda- Reynoso, M, Olvera-Ramírez, R, FrancoColin, M, Phycobiliproteins from Pseudanabaena tenuis rich in cphycoerythrin protect against $\mathrm{HgCl}_{2}$ caused oxidative stress and cellular damage in the kidney, Journal of Applied Phycology, $2010,22,495-501$. 